\title{
EL DERECHO A LA HONRA COMO LÍMITE A LA LIBERTAD DE INFORMACIÓN HASTA EL MOMENTO DE LA ACUSACIÓN PENAL
}

["The Right to Honor as Limit to the Freedom of Information up to the Moment of Filing Criminal Charges"]

\section{María Fernanda Fuentes Orellana*}

\begin{abstract}
RESUMEN
En este trabajo se propone una solución a la colisión de los derechos fundamentales a la honra y a la libertad de información, producida durante las primeras etapas del proceso penal hasta la presentación de acusación. Mediante el equilibrio de las limitaciones que se imponen recíprocamente ambos derechos y con base en principio de ponderación, se obtienen las razones doctrinales y jurisprudenciales que permiten determinar en qué momento surge la necesidad de preferir la honra por sobre la libertad de información en la instancia penal.

\section{Palabras Clave}

Acusación penal - Principio de ponderación - Derecho a la honra - Libertad de información.
\end{abstract}

[RECIBIDO el 3 de junio y ACEPTADo el 12 de septiembre de 2011].

* Estudiante de Derecho del $5^{\circ}$ año en la Universidad Católica de Temuco. Correo electrónico,mfernandafuentesorellana@gmail.com 


\section{INTRODUCCIÓN}

Desde fines del siglo XX, la sociedad chilena ha experimentado cambios orientados a fomentar el desarrollo integral de todos sus miembros. Para lo que ha utilizado distintos mecanismos, que van desde el reconocimiento de sus derechos colectivos e individuales hasta complejas políticas públicas que se van perfeccionando de forma paulatina en el tiempo.

Una vía de promoción del mencionado desarrollo integral de las personas, es la defensa de su derecho fundamental a la libertad de expresión e información. Por lo que el aumento progresivo de la información pública circulante y el mayor acceso a sus fuentes de origen, constituyen una manifestación concreta de este fenómeno; el cual, a su vez, disminuye la protección de otro derecho fundamental: la honra, y da lugar a la colisión de dos derechos fundamentales en atención a una misma actuación.

Esta colisión es aún más problemática durante las etapas previas a la presentación de la acusación penal, por las implicancias sociales que tiene en general dicho proceso. Ya que si bien no se discute la necesidad de entregar información sobre los hechos investigados en materia penal, se reconoce que es esta misma necesidad la que afecta el resguardo a la honra del imputado. Porque la falta de certeza propia de tal instancia no permite contar con información capaz de cumplir con estándares mínimos que nos aseguren que la publicación de la identidad y rostro de una persona no va a significar la vulneración de su derecho a la honra si se informa públicamente que se lleva una investigación en su contra por un determinado crimen o delito, cuando aún subsiste la posibilidad de quedar sin efecto luego de ciertas diligencias investigativas.

Ante tal problema, la solución que se propone en este trabajo es priorizar el derecho a la honra del imputado por sobre la libertad de información. Para este fin centraré mi atención sobre la relación beneficios-daños y la importancia social relativa que implica, para una sociedad democrática, la limitación de un derecho a favor del otro durante las etapas previas a la acusación penal. De modo que se logra concluir que mientras no exista al menos un grado de seguridad sobre los hechos, capaz de darles el carácter de relevancia pública, no se justifica afectar la honra de los imputados con el fin de divulgar antecedentes que aún no satisfacen los fines de la libertad de información.

A continuación se exponen en detalle las etapas y argumentaciones que me llevan a tal conclusión. Las que se inician con un ejemplo que gráfica de manera simple el conflicto de derechos, continúan con el estudio del contenido y concepto de los derechos afectados, se relacionan los casos y fundamentos dados por la jurisprudencia para poder limitar un derecho en beneficio de otro y obtener un sustento doctrinal que respalda la solución propuesta en este trabajo. 


\section{Aspectos GENERALES}

El día 16 de enero del año 2004, fue conocida públicamente la querella presentada por el SENAME en contra del sacerdote Aquiles Altamirano y Huberto Oliveros Guzmán, auxiliar de un colegio católico, por el supuesto delito de abuso sexual cometido en contra de una alumna de 12 años del mismo establecimiento ${ }^{1}$. Posteriormente, y tras meses de investigación el Ministerio Público comunicó al Juzgado de Garantía de la ciudad de Copiapó, su decisión de no perseverar en la investigación por falta de medios probatorios en que sustentar la formalización ${ }^{2}$.

$\mathrm{Al}$ ser dada a conocer públicamente la acusación de abuso sexual se generó de inmediato en la sociedad, en especial en la comuna en que ocurren estos hechos, una actitud de rechazo y desconfianza generalizada. Que se manifestó en juicios de valor y reproches públicos en diferentes redes de comunicación -respecto de quien había sido acusado de uno de los ilícitos de mayor desvalor social, por la actitud de menosprecio que representa hacia la condición de persona de la víctima ${ }^{3}$ - que obligaron a la propia Iglesia Católica a referirse sobre el tema.

Todo lo anterior confluyó para posicionar a los imputados en una especial situación de vulnerabilidad al verse expuestos a enjuiciamientos sociales y públicos a través de medios de comunicación, que pusieron en riesgo su derecho a la honra, en momentos que aún no existía certeza alguna de los acontecimientos ni un pronunciamiento judicial que lo avale. Además, grafica el problema que implica la colisión de dos derechos fundamentales: a la honra y a la libertad de información. Donde cada uno protege intereses diferentes, pero igualmente relevantes desde el punto de vista del ordenamiento jurídico y organización social.

\section{CONSIDERACIONES TEÓRICAS}

\section{Hombre y dignidad humana.}

Antes de estudiar el concepto de los derechos a la honra y libertad de información, es preciso atender a la noción de persona y dignidad humana.

${ }^{1}$ El Mercurio de 18 de enero de 2004, Obispo auxiliar alega inocencia. Enfrenta querella del Sename por violación [visible en, http, //diario.elmercurio.cl/detalle/index.asp?id $=\{$ f751 aaee-676d-4a22-872a-482d9980151d].

${ }^{2}$ Iglesia de Santiago, Copiapó, Chile, Diócesis de Copiapó, 30 de abril de 2004 [visible en, http, //vgp.iglesiadesantiago.cl/noticias.php?id=369]

${ }^{3}$ Rodríguez Collao, Luis, Delitos sexuales (Santiago, Editorial Jurídica de Chile, 2008), pp. 135-136. 
Consideraciones ambas de gran utilidad para entender el sentido y razón de ser de cada derecho.

Respecto al concepto de persona seguiré en parte las ideas de Arnold Gehlen. Quien sugiere que el hombre es un ser no especializado, que a diferencia de los animales está desprovisto de capacidad de adaptación y solo puede modificar el ambiente en que vive para su sobrevivencia llegando a complejas organizaciones que él denomina instituciones. Estas son las encargadas de brindarle seguridad, protección respecto de situaciones específicas y se presentan como formas de superar las tareas o circunstancias de importancia vital ${ }^{4}$.

Reconocida la noción de cierta desventaja o debilidad inherente del hombre, se justifica el amplio reconocimiento que hoy existe de los derechos fundamentales como medio de protección y resguardo. Por la importancia que revisten solo está permitida su afectación o restricción al concurrir motivo suficiente que lo exija, por ejemplo privar de libertad a alguien por la comisión de un crimen mediante el desarrollo de un proceso legal debidamente establecido. Es en este tipo de situaciones donde, en base a una necesidad, se permite afectar un derecho específico, sin que sea posible extender esta afectación a derechos distintos a los estrictamente establecidos, porque coloca a la persona en una instancia que aumenta, aún más y sin justificación, su condición de desventaja natural.

Unido a ello está el principio rector de estos derechos, la dignidad humana ${ }^{5}$ que permite visualizar al hombre "como ente ético espiritual, que puede por su propia naturaleza consiente y libremente autodeterminarse, formarse y actuar sobre el mundo que lo rodea" ${ }^{6}$. La persona es considerada un fin en sí mismo, no un medio, y su dignidad es independiente de su sexo, edad, capacidad intelectual, etc., que pueden aumentar, disminuir, e incluso, desaparecer dependiendo de cada persona y de las circunstancias concretas ${ }^{7}$.

${ }^{4}$ GeHLen, Arnold, Antropología filosófica. Del encuentro y descubrimiento del hombre por si mismo (Barcelona, Paidos, 1993), p. 89.

${ }^{5}$ Peces-Barba Martínez, Gregorio, Derechos fundamentales ( $3^{a}$ edición, Madrid, Editorial Latina Universitaria, 1980), p. 91.

${ }^{6}$ Von Wintrich, Zur Problematik der Grundrechte (1957), p. 15 [citado por STEIN, Ekkehart, Lehrbuch des Staatsrechts (Tübingen, 1969; traducción española de F. Sainz Moreno, bajo el título Derecho político (Madrid, Aguilar, 1973), p. 236 [citado por Fernández Segado, Francisco, Dignidad de la persona, orden valorativo y derechos fundamentales en la Constitución española de 1978, en Actas de las XXV Jornadas Chilenas de Derecho Público (Valparaíso, Edeval, 1995), II, p. 15].

${ }^{7}$ Nogueira Alcalá, Humberto, Dogmática constitucional (Talca, Editorial Universidad de Talca, 1997), p. 108. 
En otras palabras, la dignidad concreta un núcleo de existencia humana que se da en todos los derechos fundamentales. ${ }^{8}$

\section{Derecho a la honra.}

El derecho a la honra se encuentra reconocido en tratados internacionales ${ }^{9}$ y en la mayoría de las constituciones políticas ${ }^{10}$. Pero al no existir un concepto claro y preciso que indique cuál es su contenido, la doctrina y jurisprudencia se han encargado desarrollarlo progresivamente a través del tiempo.

Cada país elabora un concepto en atención a sus criterios legislativos y sociales particulares, pero guardando una estricta observancia al núcleo o contenido esencial del derecho a la honra. Por lo que solo es posible contar con leves diferencias o distinciones que miran a la especificación de su contenido.

Así, la Corte Constitucional de Colombia reconoce que la honra es la apreciación que la colectividad tiene de una persona, concepto objetivo. Distinta del honor que es la apreciación que uno tiene de sí mismo, un concepto interno ${ }^{11}$.

Por su parte, la Corte Suprema de Chile reconoce tal distinción pero entiende que es el derecho a la honra el que tiene dos alcances, uno objetivo,

${ }^{8}$ Planchadell, Andrea, El derecho fundamental a ser informado de la acusación (Valencia, Tirant lo Blanch, 1999), p. 34.

${ }^{9}$ Declaración universal de los derechos humanos, artículo 12: "Nadie será objeto de injerencias arbitrarias en su vida privada, su familia su domicilio y su correspondencia, ni de ataques a su honra y reputación. Toda persona tiene derecho a la protección de la ley contra tales injerencias y ataques"; el Pacto internacional de derechos civiles y politicos estableció en su artículo 17: "1. Nadie será objeto de injerencias arbitrarias e ilegales en su vida privada, su familia, su domicilio o su correspondencia ni de ataques ilegales a su honra y reputación. 2. Toda persona tiene derecho a la protección de la ley contra esas injerencias o esos ataques; la Convención americana sobre derechos humanos, en su artículo 11 consagra: "1. Toda persona tiene derecho al respeto de su honra y al reconocimiento de su dignidad. 2. Nadie puede ser objeto de injerencias arbitrarias o abusivas en su vida privada, en la de su familia, en su domicilio o en su correspondencia, ni de ataques ilegales a su honra y reputación.3. Toda persona tiene derecho a la protección de la ley contra esas injerencias o esos ataques".

${ }^{10}$ Constitución Politica de Colombia, artículo 21: "Se garantiza el derecho a la honra. La ley señalará la forma de su protección”; Constitución Politica de Chile, artículo 19: "La Constitución asegura a todas las personas: $\mathrm{N}^{\circ}$ 4: El respeto y protección a la vida privada y pública y a la honra de la persona y de su familia”.

${ }^{11}$ Corte Constitucional de Bogotá, sentencia C-063-1994, "[a] unque honra y honor sean corrientemente considerados como sinónimos, existe una diferencia de uso entre ellos. El honor se refiere a la conciencia del propio valor, independiente de la opinión ajena; en cambio la honra o reputación es externa, llega desde afuera, como ponderación o criterio que los demás tienen de uno, con independencia de que realmente se tenga o no honor; uno es el concepto interno -el sentimiento interno del honor-, y otro el concepto objetivo externo que se tiene de nosotros -honra". 
referido a apreciación de terceros, y otro subjetivo, que dice relación a la estimación propia o interna. Pero que para el derecho solo tiene relevancia desde el primer punto de vista. ${ }^{12}$.

La Constitución española de 1978 no contempla expresamente la honra, pero en su artículo 18,1 "Se garantiza el derecho al honor, a la intimidad personal y familiary a la propia imagen”. Por lo que el Tribunal Constitucional brinda un extenso desarrollo al derecho al honor y lo define como "[...] el derecho al respeto y al reconocimiento de la dignidad personal que se requiere para el libre desarrollo de la personalidad en la convivencia social, sin que pueda (su titular) ser escarnecido o bumillado ante uno mismo o los demás [...]"13. Declarando a su vez que el honor, al igual que la honra, consiste en la opinión que las gentes tienen de una persona, buena o positiva ${ }^{14}$.

En adelante y para los fines de este trabajo voy a considerar que la honra es el derecho fundamental que busca proteger el valor intrínseco de las personas frente a la sociedad y evitar todo menosprecio o acto difamatorio que lesione la apreciación o fama que los demás tengan de una persona. Sin perjuicio de las precisiones que se realicen más adelante con el desarrollo de este trabajo.

\section{Derecho a la libertad de información.}

En términos generales, el derecho a la libertad de información consiste en la libertad de emitir opinión e informar acontecimientos a terceros, sin censura previa y por cualquier medio idóneo destinado al efecto ${ }^{15}$. Lo que hace extensible su protección a la posibilidad acceder a las respectivas fuentes de información.

Para explicarlo me apoyaré de lo señalado por la Corte Europea de Derechos Humanos, que considera a la libertad de información como una especie del derecho a la libertad de expresión ${ }^{16}$. En tal sentido, expresa: "[...] es uno de los principales fundamentos de una sociedad democrática y una de las condiciones más importantes para su progreso y el desarrollo individual $[\ldots]^{\prime \prime}$, y reconoce también la existencia de limitaciones, pero que atendida la relevancia misma de este derecho, toda formalidad, condición, restricción o sanción impuesta en la materia no sólo va a tener que responder a un fin legítimo, sino que deberá ser proporcionada al mismo ${ }^{18}$.

\footnotetext{
${ }^{12}$ Corte Suprema, sentencia, rol N ${ }^{\circ} 8140-2009$, de 19 de enero de 2010.

${ }^{13}$ Sentencia del Tribunal Constitucional de España, $N^{\circ} 219 / 92$, de 3 de diciembre de 1992.

${ }^{14}$ Sentencia del Tribunal Constitucional de España, $N^{\circ} 223 / 92$, de 14 de diciembre de 1992.

${ }^{15} \mathrm{CEDH}$, caso "Handyside contra Reino Unido", 7 de diciembre de 1976.

${ }^{16} \mathrm{CEDH}$, caso "The Sunday Times", 26 abril 1979.

${ }^{17} \mathrm{CEDH}$, caso "Lingens contra Austria”, de 8 de julio de 1986.

${ }^{18}$ Fernández Segado, Francisco, La libertad de expresión en la doctrina del
} 


\section{Conflicto de derechos.}

En ambos derechos hay intereses jurídicos resguardados que revisten importancia para la vida en sociedad. Sin embargo, existen situaciones -como la expuesta en la primera sección- en que ambos entran en conflicto y su solución es más compleja que simplemente establecer una regla general que determine cuál es superior. Si bien la doctrina y jurisprudencia en determinados casos han manifestado que uno prevalece sobre el otro, como por ejemplo el derecho a la honra en caso Martorell, ante los tribunales nacionales, o el derecho a la libertad de expresión e información en el mismo caso pero ante la Comisión Interamericana de Derechos Humanos, la mayoría de las veces han sido insistentes en sostener que los derechos fundamentales no se jerarquizan, sino que solo deben ser ponderados cuidadosamente, respetando ciertos criterios como por ejemplo: la relevancia pública de la información ${ }^{19}$, existencia de un mínimo de diligencia en la comprobación de los hechos o la actitud positiva del actor hacia la verdad ${ }^{20}$, que el grado de diligencia sea razonable y proporcionado a las circunstancias, que no hay intromisión ilegítima en la honra de la persona cuando se realizan críticas acerbas ${ }^{21}$ y que sean injerencia previstas por la ley ${ }^{22}$.

Criterios que solo constituyen lineamientos generales, ya que su resolución no es tan simple y se ve reflejado en el caso expuesto a modo de ejemplo, donde no se manifiestan vulneraciones a estos criterios, pero el hecho sobre el que recae la información es falso o al menos no se logró acreditar a fin de llevar a cabo, al menos, la acusación. Pero al vincular a los afectados con un delito en calidad de imputados, se dio lugar a una serie de juicios públicos paralelos en su contra anteriores a esta actuación del Ministerio Público, que evidencia tanto una vulneración de sus derechos a la honra.

En consecuencia, es imposible dar una adecuada solución a la colisión de derechos en base -únicamente- a la aplicación de criterios como los recién expuestos. Toda vez que hay muchas situaciones en que la información entregada no soporta siquiera una evaluación sobre su relevancia pública.

La solución definitiva a los casos de colisión, parece estar entregada en

Tribunal Europeo de Derechos Humanos, en Revista de Estudios Politicos, 70 (1990), p. 96 [visible en internet, http, //www.cepc.es/rap/Publicaciones/Revistas/3/ REPNE_070_094.pdf].

${ }^{19}$ Grisolía Corbatón, Francisco. Libertad de expresión y derecho a la honra (Santiago, LexisNexis, 2004), pp 110-111.

${ }^{20}$ Ibíd., p. 111.

${ }^{21}$ Nogueira Alcalá, Humberto, Pautas para superar las tensiones entre los derechos a la libertad de opinión e información y los derechos a la honra y la vida privada, en Revista de Derecho 17 (Valdivia, 2004), pp. 139-160.

${ }^{22} \mathrm{CEDH}$, caso "Barthold", 25 de marzo de 1985. 
alto grado a valoración de las circunstancias que concurren en cada caso, y también a la subjetividad del juez. Por lo que es imperante contar con un argumento capaz de soportar estas críticas y que brinde mayor certeza sobre la resolución de tal colisión.

\section{EN BUSCA DE UNA SOLUCIÓN}

\section{Limitaciones entre derechos fundamentales.}

Con el ejemplo del Padre Aquiles, se muestra la colisión de derechos y la inconveniencia de acudir netamente a elementos fácticos para su resolución. En consecuencia, surge la necesidad de contar con elementos argumentativos de fondo, capaces de superar las dificultades que hasta el momento se plantean.

Para ello debemos considerar que los derechos fundamentales no son absolutos. Si no es posible dar entera satisfacción a dos o más derechos se deben establecer limitaciones recíprocas entre ellos, las que son reconocidas incluso de manera expresa en disposiciones legales, como por ejemplo en el artículo 10 de la Convención Europea: "Todapersona tiene derecho a la libertad de expresión. Este derecho comprende la libertad de opinión y la libertad de recibir o de comunicar informaciones e ideas sin que puedan injerirse en ellas las autoridades públicas y sin consideración de fronteras (...). 2. El ejercicio de estas libertades, que implica deberes y responsabilidades, podrá someterse a determinadas formalidades, condiciones, restricciones o sanciones previstas por la ley que sean medidas necesarias en una sociedad democrática para la seguridad nacional, la integridad territorial o la seguridad pública, la defensa del orden y la prevención del delito, la protección de la salud o de la moral, la protección de la reputación o de los derechos ajenos para impedir la divulgación de informaciones reservadas o para garantizar la autoridad y la imparcialidad del Poder Judicial"23.

Para tales limitaciones, es necesario tener presente el respeto al contenido central de cada derecho, evitando que no pueda ser ejercido, se obstruya su ejercicio en exceso o lo despojen de su necesaria protección, dejándolo vacío de contenido ${ }^{24}$. Es respecto a este contenido de cada derecho en que se debe centrar la mayor atención en casos de conflicto, porque supone no solo un límite a las actuaciones de particulares, sino también de los órganos del Estado.

La jurisprudencia y doctrina española han aclarado que para conocer este

${ }^{23}$ Convenio para la protección de los derechos humanos y de las libertades fundamentales (Secretaría del Tribunal Europeo de Derechos Humanos, junio de 2010).

${ }^{24}$ Planchadell, Andrea. cit. (n. 8), p. 32. 
contenido esencial en cada derecho, se hay que atender a dos elementos: $i$ ) La naturaleza jurídica del derecho, es decir, lo que generalmente se entiende por él en doctrina y jurisprudencia ${ }^{25}$; y $i$ ) Los intereses jurídicamente protegidos, es decir, la parte del derecho que permite la efectiva protección de de los bienes jurídicos resguardados ${ }^{26}$.

$\mathrm{Al}$ momento de referirme a limitaciones entre derechos, asumo -en adelante- que es menester mantener una estricta observancia a los dos principios enunciados. Es decir, que no existe un derecho fundamental de carácter absoluto y toda limitación debe respetar el contenido esencial de cada derecho. A fin de lograr, primero, proponer una solución satisfactoria al problema planteado y segundo, evitar el riesgo de extender la discusión a puntos no sometidos a discusión en este trabajo.

\section{Aplicación de las consideraciones relativas a las limitaciones.}

De acuerdo a los elementos recién expuestos, resulta que el contenido del derecho a la honra es la buena fama o imagen ante terceros. Como un medio para lograr protección frente a la descripción inexacta de la vida privada o frente a alguna atribución errónea a una persona de un rasgo que presumiblemente va a perjudicarle ${ }^{27}$.

El derecho a la libertad de información consiste en la libertad de emitir opinión e informar sin censura previa y constituye uno de los fundamentos esenciales de tal sociedad [democrática], una de las condiciones primordiales para su progreso y el desarrollo de los hombres ${ }^{28}$.

Ahora, identificado el contenido de cada uno, resulta importante determinar en qué momento surge la real necesidad de limitar un derecho a favor de otro. En tal sentido los fallos de la Corte Europea, sobre la base del artículo 10.2 de la Convención, señalan que esta debe ser necesaria en una sociedad democrática ${ }^{29}$. La jurisprudencia de la Corte tiene como punto de partida el carácter limitado de los derechos a la libertad de expresión y de información, en base al reiterado artículo $10 \mathrm{~N}^{\circ} 2$. Por lo que acepta la restricción al ejercicio de estos en beneficio de otros derechos como la honra, intimidad, etcétera ${ }^{30}$.

${ }^{25}$ Ibíd., p. 37.

${ }^{26}$ Ibíd.

${ }^{27}$ Alegre Martínez, Miguel, El derecho a la propia imagen (Madrid, Tecnos, 1997), p. 43.

${ }^{28} \mathrm{CEDH}$, caso "Handyside contra Reino Unido", 7 de diciembre de 1976.

${ }^{29} \mathrm{CEDH}$, caso "Tolstoy Miloslavsky", de 13 de julio de 1995.

${ }^{30}$ CASTILlo Córdova, Luis, Un caso de internacionalización y constitucionalización. Las libertad de expresión e información en la jurisprudencia del TCDHy del TC, en Boletin Mexicano de Derecho Comparado, 40 (2007) 119, pp. 396-397. 
En el mismo sentido, se pronuncia el Tribunal Constitucional Español, que si bien se refiere al carácter preferente ${ }^{31}$ de los derechos a la libertad de expresión y de información, ésta preferencia es solo conceptual y admite restricciones al igual que la Corte Europea de Derecho Humanos. Reconoce la imposibilidad de no dejar vacíos de contenido los derechos personales en beneficio a la libertad de información y solo permite su superioridad en la medida que sea necesaria para contribuir a la formación de una opinión pública libre en un Estado democrático ${ }^{32}$.

Independiente de las diferencias conceptuales de cada tribunal, lo importante es que ambos destacan que las restricciones a las libertades y derechos personales solo serán procedentes si es necesario asegurar tanto la entrega de una información pública libre en la sociedad democrática, como la vigencia de otros derechos fundamentales, por ejemplo la honra ${ }^{33}$.

En lo que respecta a las etapas del proceso penal previas a la acusación, determinar el momento en que surge tal necesidad, requiere finalmente la evaluación de tres circunstancias concretas presentes en este momento procesal: Interés social y relevancia de la información; relevancia del proceso penal y grado de diligencia del comunicador social; y, perjuicios y responsabilidad.

a) Interés social, relevancia de la información. No hay duda del interés social que supone la exposición de los antecedentes relevantes del proceso penal, en especial las audiencias y los debates entre las partes. Pero es discutible que esté presente el mismo interés al momento de publicar los datos sobre los que se funda la detención e incluso las audiencias previas al juicio oral, donde solo existe una especie de expectativa procesal, que se facultaría a los medios de comunicación a informar sobre las generalidades del caso, sin individualizar a los involucrados ni mostrarlos públicamente.

b) Relevancia del proceso penal y grado de diligencia del comunicador, sea este un medio de comunicación o una persona natural que utilice las redes sociales. El proceso penal constituye hoy en día una de las instancias de mayor relevancia social, porque exige el cumplimiento de todas y cada una de las solemnidades establecidas para resguardar, tanto la objetividad como la seguridad del proceso mismo, siendo necesario actuar con un nivel de diligencia mayor al requerido comúnmente respecto de otras instancias. Esto supone que todo medio de comunicación masivo y persona natural que pretenda informar sobre la identidad de los

${ }^{31}$ Sentencia del Tribunal Constitucional de España $N^{\circ}$ 172/1990, 12 de noviembre de 1990.

${ }^{32}$ Sentencia del Tribunal Constitucional de España $N^{\circ} 171 / 1990,12$ de noviembre de 1990.

${ }^{33}$ Sentencia del Tribunal Constitucional de España N ${ }^{\circ}$ 171/1990, 12 de noviembre de 1990 . 
imputados, se debe contar con un antecedente de reconocido valor jurídico, como la sentencia firme y ejecutoria, de preferencia, o bien, la acusación penal del Ministerio Público. Mientras ello no ocurra solo se puede comunicar antecedentes generales del proceso.

c) Perjuicios y responsabilidad. La información difundida puede causar perjuicios materializados de diferentes formas, que van desde el reproche personal de sus más cercanos, hasta la pérdida de vínculos familiares o incluso laborales.

Sobre esta última faceta, se pueden observar con claridad los efectos que acarrea el daño a la honra u honor de una persona por la imputación de un crimen o simple delito. Al respecto, el Tribunal Constitucional reconoce la importancia que en nuestros días adquiere la actividad profesional como " [...] una de las formas más destacadas de manifestación externa de la personalidad $y$ de la relación del individuo con el resto de la colectividad, de forma que la descalificación injuriosa o innecesaria de ese comportamiento tiene un especial e intenso efecto sobre dicha relación y sobre lo que los demás puedan pensar de unapersona, repercutiendo tanto en los resultados patrimoniales de su actividad como en la imagen personal que de ella se tenga [...]"34.

Además, no es ajena a esta materia la discusión sobre los efectos que pueden tener en el juicio o incluso en la sentencia, el desarrollo de juicios paralelos en los medios de comunicación. Ya que según la Corte Europea de Derechos Humanios, las limitaciones del el artículo 10, deben garantizar la autoridad y la imparcialidad del poder judicial ${ }^{35} \mathrm{y}$ agrega que lo importante no es evitar la actividad de los medios de comunicación, respecto a los temas de relevancia pública, sino la espectacularización de la información sobre lo que se debate en juicio ${ }^{36}$.

De estas consideraciones se plantea la siguiente pregunta: ¿Cuándo surge el interés público en la información capaz de justificar su divulgación?

Con el análisis realizado hasta el momento, se extrae que libertad de información de una sociedad democrática se satisface con la entrega de antecedentes obtenidos de fuentes fidedignas y que recaigan sobre el contenido sustancial de las materias. Pues si esta no es capaz de cumplir ciertos estándares de seguridad mínimos difícilmente se cumple el objetivo de contribuir a formar una sociedad pluralista y libre de opinar y decidir.

En lo referente al proceso penal, este interés se verifica al ser presentada la acusación. Porque en este momento las diligencias de investigación ya fueron realizadas, los resultados obtenidos fueron suficientes para

${ }^{34}$ Sentencia del Tribunal Constitucional de España $N^{\circ}$ 180/1999, 11 de octubre de 1999.

${ }^{35} \mathrm{CEDH}$, caso "Worm con Australia", 29 de agosto 1997.

${ }^{36} \mathrm{CEDH}$, “Sunday Times con Reino Unido," 27 de octubre 1978. 
permitir al Ministerio Público sostener una acusación y enfocar sus esfuerzos hacia una sentencia condenatoria por los crímenes o simples delitos que, a su juicio, se encuentran acreditados por sus medios probatorios recabados.

$\mathrm{Al}$ instante de presentar la acusación penal, toda publicación relativa a la identidad del o los involucrados no supone, necesariamente, una lesión a su honra. Porque - partiendo de la base que las gestiones que realiza el Ministerio Público son serias, objetivas, tendientes a esclarecer los hechos objeto del proceso y que está en juego la libertad de una o más personas- el riesgo de atribuir la comisión de un hecho delictivo a quien no ha tenido participación en él disminuye considerablemente luego de concluido el período de investigación.

\section{Propuesta de UNA SOlución}

Una vez establecida la pertinencia de limitar el derecho a la libertad de información a favor de la honra, en un momento especial y determinado del proceso penal, cabe señalar cuál es el fundamento teórico en que se sustenta. Pero antes haré dos menciones: $i$ ) Se debe citar nuevamente la relevancia de la dignidad humana, como el principio rector de todos los derechos fundamentales, en que la protección dada por el constituyente es el minimun invulnerable para ejercicio de los derechos, que no se puede transgredir; y ii) El derecho a la honra, al emanar de la dignidad humana, adquiere un carácter netamente individual, que mira solo a su titular en sí mismo y no a la colectividad. Pues estos “[...] derechos no están supeditados a las decisiones de las mayorías a través de un proceso democrático, ya que ellos están destinados a proteger a individuos o minorías contra la posibilidad de ser sacrificados en aras de la mayor felicidad del mayor número [...]". ${ }^{37}$ Por lo que es inaceptable permitir su vulneración en post de satisfacer los intereses colectivos, salvo que exista la extrema necesidad que la justifique. Solo en tales casos es posible que se equilibren ambos derechos, y la libertad de información que mira a la colectividad pueda prevalecer por sobre la honra.

\section{La necesidad.}

Esta línea de argumentación se refuerza con el principio de ponderación de Robert Alexy. Pues conforme a él, en casos en que para el ejercicio de un derecho es precisa la afectación de otro, se deben considerar los tres subprincipios de la ponderación: idoneidad, necesidad y ponderación en sentido

${ }^{37}$ Nino, Carlos Santiago. Legítima defensa. Fundamentación y régimen jurídico (Buenos Aires, Astrea, 1982), p. 58. 
estricto. De ellos, el que cobra especial relevancia en el caso de estudio es el de la necesidad. Que exige que de dos medios igualmente idóneos para satisfacer un derecho se debe optar por aquel más benigno con el derecho fundamental afectado ${ }^{38}$.

Si el derecho que se pretende satisfacer es la libertad de información, existen dos medios para logarlo: $i$ ) que se dé a conocer la identidad del imputado en las primeras gestiones investigativas, pero con ello se corre el riesgo de afectar su derecho a la honra, en los términos ya indicados; y ii) que la misma información sea dada a conocer una vez presentada la acusación penal, medio que resulta idóneo al no afectar el derecho individual mencionado. Por ejemplo, de la interpretación del artículo 11 de la Convención Americana, en relación al artículo 32.2, se extrae que las medidas de restricción no solo deben ser necesarias, sino estrictamente necesarias para proteger un derecho ${ }^{39}$.

Si no existe una investigación sobre los hechos, no se puede ejercer el derecho a la información respecto a aquello que aún es susceptible de ser negado ante diligencias investigativas obligatorias en una etapa posterior del proceso. Por lo que no se logra contribuir a mantener el pluralismo político, libertad de conciencia y dignidad humana, que garantice la existencia de una sociedad democrática.

En consecuencia, si la información entregada no contribuye a estos fines y solo existe la posibilidad de que en un tiempo posterior se logre justificar la necesidad de divulgar públicamente tales antecedentes, se corre el innecesario riesgo de transgredir el derecho a la honra. En especial, si en la instancia definitiva se establece que el imputado debe ser absuelto de todo cargo.

Afectación que adquiere la intensidad de grave, debido a los efectos sociales que significa la imputación de un delito en relación al derecho a la honra de las personas. Mientras que la satisfacción del derecho a la información en estas condiciones es solo leve, por lo que no hay una real necesidad de sacrificar con tal intensidad el derecho a la honra en beneficio de una información que aún no está respaldada por investigación alguna ni reviste el carácter de relevancia pública exigida, tal como se señaló en apartados anteriores.

${ }^{38}$ Alexy, Robert. Epílogo a la teoría de los derechos fundamentales. Madrid, Centro de Estudios Fundación de Beneficentia et Peritia Iuris, 2004), p. 41

${ }^{39}$ Convención Americana sobre derechos humanos, artículo 11, "Protección de la Honra y de la Dignidad, 1. Toda persona tiene derecho al respeto de su honra y al reconocimiento de su dignidad. 2. Nadie puede ser objeto de injerencias arbitrarias o abusivas en su vida privada, en la de su familia, en su domicilio o en su correspondencia, ni de ataques ilegales a su honra o reputación. 3. Toda persona tiene derecho a la protección de la ley contra esas injerencias o esos ataques"; artículo 32., "Correlación entre Deberes y Derechos, 1. Toda persona tiene deberes para con la familia, la comunidad y la humanidad. 2. Los derechos de cada persona están limitados por los derechos de los demás, por la seguridad de todos y por las justas exigencias del bien común, en una sociedad democrática". 


\section{Proporcionalidad en sentido estricto.}

Para profundizar este razonamiento es recomendable abordar el conflicto de derechos fundamentales atendiendo nuevamente al principio de proporcionalidad, pero ahora en sentido estricto. Que tal como lo concibe Aharón Barak, es "[...] una prueba consecuentes y requiere una adecuada relación entre el beneficio obtenido por la ley que limita un derecho humano y el daño causado al derecho por su limitación [...]”彺, que en definitiva equilibra las metas alcanzadas con las limitaciones de los derechos. Para tal equilibrio se determina el peso de cada elemento según la "[...] importancia social relativa atribuida a cada uno de los principios en conflicto, y evalúa la importancia para la sociedad de los beneficios adquiridos por la realización del objetivo de la ley, frente a la importancia para la sociedad de la prevención de la limitación de los derechos humanos [...]”¹.

El beneficio obtenido con la realización de un objetivo depende de la existencia de un grado de urgencia capaz de justificar la limitación del derecho, unido al examen de la probabilidad de lograr el objetivo. El que a su vez depende de los datos de hecho y el pronóstico sobre la posibilidad de realizar el objetivo adecuado ${ }^{42}$. La importancia que se concede al derecho mismo y la prevención de su limitación, se determina de acuerdo a las concepciones fundamentales de esa sociedad, y a la probabilidad delimitación real del derecho ${ }^{43}$.

Conforme al principio de proporcionalidad en sentido estricto, el derecho a la libertad de información no justifica que se limite el derecho a la honra en las etapas previas a la acusación penal. Porque no existe aún urgencia que apoye limitar el derecho a la honra y la probabilidad de lograr el objetivo satisfacer el derecho libertad de información - durante las primeras etapas es baja, atendida que aún faltan los antecedentes en que respaldar cualquier acusación.

La importancia que la sociedad atribuye a la prevención de limitaciones al derecho a la honra es alta, por la fuerte desaprobación social que sufre quien es acusado judicialmente de la comisión de un crimen o simple delito. En especial aquellos que atentan contra los bienes jurídicos de mayor protección, con todas las consecuencias familiares, laborales y personales que ello significa. O dicho en otros términos la importancia social relativa del primer derecho es insuficiente.

\footnotetext{
${ }^{40}$ BArak, Aharon, Proportionality and Principled Balancing, en Law \& Ethics of Human Rights, 4 (2010) pp. 7

${ }^{41}$ Ibíd., pp. 7-8.

${ }^{42}$ Ibíd., pp. 8-9.

${ }^{43}$ Ibíd., p. 10.
} 


\section{Situación de los grupos desventajados} FRENTE A LA PROTECCIÓN DE LA HONRA

Antes de dar por concluido este trabajo, quiero exponer la situación de desventaja que tienen ciertos grupos de personas, en especial en el proceso penal. Me refiero a quienes por sus características culturales o de edad, se encuentran de manera constante en desventaja respecto al resto de la sociedad, como por ejemplo los menores de 18 años.

No pretendo extenderme sobre el tema sino solo exponer la siguiente pregunta: ¿es este grupo merecedor de una protección mayor a su derecho a la honra, en el proceso penal?

Si se acepta que en condiciones normales todo imputado asume cierta desventaja ante el Estado, al estar expuesto a un peligro cierto de sufrir una restricción o privación de su derecho a la libertad y que requiere el resguardo de sus demás derechos fundamentales - por lo que hay todo un sistema de leyes procesales y constitucionales creadas al efecto. Se puede sostener, entonces, que quien en condiciones normales ostente una situación de inferioridad frente al común de sus pares, merece una protección más fuerte de sus derechos fundamentales, especialmente de su honra, en base a la necesidad de dar un trato de igualdad a los miembros de la sociedad ${ }^{44}$.

Idea que se puede explicar de mejor manera, al tomar como ejemplo la situación de un menor de edad, que sin comprender el significado de sus actos, comete un delito y es expuesto públicamente, en base al ejercicio al derecho de libertad de información. Los efectos nocivos para la vida futura del menor son amplios si se recuerda la importancia que tiene para el crecimiento de una persona las situaciones a que se ve expuesto en sus primeros años. Por lo que planteo la posibilidad de limitar de manera seria el derecho a la libertad de información respecto a la comisión de un delito por un menor de edad, y que se traduce en la imposibilidad absoluta de individualizarlo, sea por nombre, imagen o rasgos, para evitar una afección a su desarrollo y honra frente a la sociedad, aún si se obtiene una sentencia condenatoria ${ }^{45}$.

${ }^{44}$ Gargarella, Roberto, Derecho y grupos desventajados (Barcelona, Gedisa, 1999), pp. 137-167

${ }^{45}$ El 24 de mayo de 2011, un fallo del Tribunal Constitucional chileno sostuvo la constitucionalidad del artículo 2331 de Código Civil. Tema sobre el que ya se había pronunciado con anterioridad en sentido contrario y respecto del cual no hay consenso en doctrina ni en la sede jurisprudencial. Resulta interesante observar los argumentos vertidos en esta oportunidad y la conclusión obtenida, en especial por la estrecha vinculación que tiene al tema objeto de este trabajo. Pero por motivos de tiempo y atendido el carácter reciente del fallo no me puedo referir a él en esta oportunidad. Aunque solo quiero destacar lo controversial de la discusión, que es un tema que aún no está zanjado 


\section{Conclusión}

En este trabajo se desarrolló el problema que surge con la colisión de los derechos fundamentales a la libertad de información y la honra durante el proceso penal. Centrando el objeto de estudio a la situación que se presenta en las primeras etapas, donde aún no se formula la acusación ante el Tribunal de Garantía competente. Se expone el problema, las consecuencias que derivan de él y se propone una solución que no supone la afectación de un derecho en beneficio del otro y tiene en especial consideración las características propias del proceso penal y sus diferentes momentos.

La solución obtenida es considerar el derecho a honra de los imputados como un límite al ejercicio de la libertad de información durante las etapas previas a la acusación penal. Restricción aplicable no solo a los medios de comunicación, sino también a los particulares que utilizan diferentes redes sociales para difundir antecedentes. Lo que se obtiene luego de un análisis progresivo de los diferentes elementos y consideraciones que se encuentran presentes en esta instancia y los intereses jurídicos protegidos por los derechos a la honra y libertad de información, respectivamente.

Ante una colisión de derechos fundamentales, cabe recordar que ninguno es de carácter absoluto y toda limitación debe respetar el contenido esencial de cada derecho. Por lo que solo se puede sostener la predominancia de uno por sobre el otro mientras exista un motivo suficiente que justifique su preferencia, de lo contrario se corre el riesgo de transgredir un derecho fundamental.

Para que predomine la libertad de información de una sociedad democrática, se exige la entrega de antecedentes obtenidos de fuentes fidedignas y que recaigan sobre el contenido sustancial de las materias. Es decir, que sea capaz de cumplir ciertos estándares de seguridad mínimos para contribuir a formar y mantener una sociedad pluralista y libre de opinar y decidir.

En lo relativo al proceso penal, el interés que justifica la entrega de información sobre la identidad de los imputados surge una vez concluida la investigación y presentada la acusación penal. Momento en que las diligencias de investigación ya fueron realizadas y los resultados obtenidos son suficientes para permitir al Ministerio Público sostener una acusación tendiente a obtener sentencia definitiva. Pues, si no existe una investigación que funde las imputaciones, no se puede pretender ejercer el derecho a la libertad de información respecto a hechos que aún son inciertos.

Si faltan tales requisitos solo se corre el innecesario riesgo de transgredir el derecho a la honra. Afectación que adquiere la intensidad de grave, en

y sobre el cual se pueden presentar distintas posturas, siempre que respeten los principios orientadores de nuestro ordenamiento jurídico. 
contraposición a una satisfacción del derecho a la información solo leve, porque su importancia social relativa en estas condiciones es insuficiente para que se justifique afectar la honra, atendido que aún faltan los antecedentes en que respaldar la imputación del ilícito penal.

\section{BIBLIOGRAFÍA}

\section{Literatura}

Alegre Martínez, Miguel, El derecho a la propia imagen (Madrid, Tecnos, 1997). Alexy, Robert, Epilogo a la teoría de los derechos fundamentales (Madrid, Centro de Estudios Fundación de Beneficentia et Peritia Iuris, 2004).

BARAK, Aharon, Proportionality and Principled Balancing, en Law \& Ethics of Human Rights, 4 (2010).

Castillo Córdova, Luis. Un caso de internacionalización y constitucionalización. La libertad de expresión e información en la jurisprudencia del TCDH y del TC, en Boletin Mexicano de Derecho Comparado, 40 (2007).

Fernández Segado, Francisco, La libertad de expresión en la doctrina del tribunal europeo de derechos humanos, en Revista de Estudios Politicos, 70 (octubre-diciembre de 1990).

Fernández Segado, Francisco, Dignidad de la persona, orden valorativo y derechos fundamentales en la Constitución española de 1978, en Actas de las XXV Jornadas Chilenas de Derecho Público (Valparaíso, Edeval, 1995), II.

Gargarella, Roberto, Derecho y grupos desventajados (Barcelona, Gedisa, 1999).

GeHLen, Arnold, Antropología filosófica. Del encuentro y descubrimiento del hombrepor si mismo (Barcelona, Paidos, 1993).

Nino, Carlos Santiago, Legitima defensa. Fundamentación y régimen jurídico (Buenos Aires, Astrea, 1982.

Nogueira Alcalá, Humberto, Dogmática constitucional (Talca, Editorial Universidad de Talca, 1997).

Nogueira Alcalá, Humberto, Pautas para superar las tensiones entre los derechos a la libertad de opinión e información y los derechos a la honra y la vida privada, en Revista de Derecho, 17 (Valdivia, 2004).

Peces-Barba Martinez, Gregorio, Derechos Fundamentales ( $3^{a}$ edición, Madrid, Editorial Latina Universitaria, 1980).

Planchadell, Andrea, El derecho fundamental a ser informado de la acusación (Valencia, Tirant lo Blanch, 1999).

Rodríguez Collao, Luis, Delitos sexuales (Chile, Editorial Jurídica, 2008).

Zamora JiméneZ, Arturo, Bien jurídico y consentimiento en Derecho penal, en Revista Letras Jurídicas, 6 (2008).

Textos normativos

Constitución Politica de Colombia de 1991.

Convención americana sobre derechos humanos, noviembre de 1969.

Convenio para la protección de los derechos humanos y de las libertades fundamentales, junio de 2010.

Declaración universal de los derechos humanos, 10 diciembre de 1948.

Pacto internacional de derechos civiles, 16 de diciembre de 1966. 
Jurisprudencia

Corte Constitucional de Bogotá, sentencia C-063-1994.

Corte Europea de Derechos Humanos, Caso "Barthold”, 25 de marzo de 1985.

Corte Europea de Derechos Humanos, Caso "Handyside contra Reino Unido", 7 de diciembre de 1976.

Corte Europea de Derechos Humanos, Caso "Lingens contra Austria”, de 8 de julio de 1986.

Corte Europea de Derechos Humanos, Caso “The Sunday Times”, 26 abril 1979.

Corte Europea de Derechos Humanos, Caso "Tolstoy Miloslavsky", de 13 de julio de 1995.

Corte Europea de Derechos Humanos, Caso "Worm con Australia", 29 de agosto 1997.

Corte Europea de Derechos Humanos, "Sunday Times con Reino Unido", 27 de octubre 1978.

Corte Suprema, Chile, Sentencia rol No 8140-2009, 19 de enero de 2010.

Tribunal Constitucional de Chile, sentencia $\mathrm{N}^{\circ} 171 / 1990$, de 12 de noviembre de 1990.

Tribunal Constitucional de Chile, sentencia $N^{\circ}$ 172/1990, 12 de noviembre de 1990.

Tribunal Constitucional de Chile, sentencia $\mathrm{N}^{\circ}$ 180/1999, 11 de octubre de 1999.

Tribunal Constitucional de Chile, sentencia N²19/92, 3 de diciembre de 1992.

Tribunal Constitucional de Chile, sentencia N²23/92, de 14 de diciembre de 1992. 